American Journal of Environmental Sciences 5 (3): 325-329, 2009

ISSN 1553-345X

(C) 2009 Science Publications

\title{
Analysis of Some Pesticide Residues in Cauliflower by High Performance Liquid Chromatography
}

\author{
${ }^{1,2}$ Sheheli Islam, ${ }^{2}$ Nazneen Afrin,,${ }^{2,3}$ Mohammad Shawkat Hossain, ${ }^{2}$ Nilufar Nahar, \\ ${ }^{2}$ Mohammad Mosihuzzaman and ${ }^{2}$ Mohammad Iqbal Rouf Mamun \\ ${ }^{1}$ Laboratory of Biological and Environmental Systems, Kochi University, Nankokushi, \\ Monobe B 200, Kochi 783-8502, Japan \\ ${ }^{2}$ Department of Chemistry, University of Dhaka, Dhaka-1000, Bangladesh \\ ${ }^{3}$ Research Institute of Molecular Genetics, Kochi University, Nankokushi, \\ Monobe B 200, Kochi 783-8502, Japan
}

\begin{abstract}
Problem statement: Increased use of chemicals on vegetables started gaining momentum and continued its up-trend in Bangladesh. Wide spread use of pesticides in agriculture concern of residue accumulation, which may remain in food and agricultural environment causing concern of human health and risking ecological balance. Attempt made to ensure that their applications were correct and safe and result in no residues in food beyond codex developed maximum residue limits. Approach: This study reported a method based on High Performance Liquid Chromatography (HPLC) for determination of pesticide residues used in Cauliflower. Cauliflower sprayed with, 4 different pesticides (diazinon, malathion, chlorpyrifos and cypermethrin) at recommended dose and double of recommended dose were analyzed for their residual contents. Samples were collected at same day after application of pesticide. Commercial samples of cauliflowers were collected from different markets of Dhaka city. Reversed-phase HPLC system with UV detection was used for the separation, identification and quantification of all these analytes using acetonitrile-water (70:30, v/v) as mobile phase. Results: Limit of detection of $0.02 \mathrm{mg} \mathrm{kg}^{-1}$ was obtained. Calibration curves that constructed for the analytes spiked into samples followed linear relationships with good correlation coefficients $\left(\mathrm{R}^{2}>0.990\right)$. In the analysis, from vegetables treated with diazinon and chlorpyrifos at recommended and double of recommended doses, residual amounts above respective MRL values were found. Conclusion: Method used permitted the determination of these pesticides in cauliflower at concentration level demanded by current legislation. Attention paid on excess use or abuse of pesticides by judicious application for safety of public health in Bangladesh. Additional data to monitor residues in food and to fill gaps in current knowledge would be helpful in assessing human exposure risks from ingestion of contaminated cauliflower or other vegetables.
\end{abstract}

Key words: Pesticide residues, cauliflower, high performance liquid chromatography, maximum residue limits

\section{INTRODUCTION}

Bangladesh is predominantly an agricultural country with an area of 1, 47,570 sq. km. Agriculture plays an important role in the lives of Bangladeshi people. The major crops grown in the country are rice, wheat, jute, potato, sugarcane, vegetables and tea. Cauliflower (Brassica oleracea var Botrytis) is produced in many areas of Bangladesh. The acreage of cauliflower cultivation in Bangladesh is about 9,400 ha and the annual production amounts to about $73,000 \mathrm{~m}$ tons ${ }^{[1]}$. Cauliflower is low in fat, high in dietary fiber, contains water and vitamin $\mathrm{C}$, possessing a very high nutritional density. The warm and humid climatic condition of the country, increase use of modern high yielding varieties of crops and more use of chemical fertilizers are highly favorable for development and multiplication of pests and diseases. In Bangladesh context, the cauliflower growers have been using the pesticides frequently to have the higher yield. But the overdoses of pesticides make the residue problem, which might pollute our food and be harmful for our

Corresponding Author: Sheheli Islam, Laboratory of Biological and Environmental Systems, Faculty of Agriculture, Kochi University, Nankokushi, Monobe B200, Kochi 783-8502, Japan Tel: +81-88-864-1237 
health. It has been reported that some of the pesticides are being used on northern part of the country where no pre-harvest time frame after application is maintained. What is most alarming is that pesticide use is very indiscriminate in Bangladesh. There are areas where pesticides are used in excessive quantities. Such situations make monitoring and assessment of pesticide contamination very difficult. Therefore, pesticide residue is becoming a major food safety concern of consumers and governments.

Although the government is concerned about pesticide residues in the food and the environment, staff and facilities to conduct the necessary monitoring programs are not available. In addition the country is not yet established legal limits for residues and depends upon Codex allowable limit which are not always proposed for all crops and major pesticides used with in the country. So in order to remove residual effect of pesticides, which are toxic, we should know the exact dose which should be recommended to the farmer and the harvest time after spray of each pesticide so that the amount of residual pesticides in vegetables might be lower than the acceptable range.

The extraction and quantitation of pesticide residues in food matrix mostly involved liquid-liquid extraction with a great variety of solvents and adsorbents for clean up. Analytical techniques such as Gas Chromatography (GC) and High Performance Liquid Chromatography (HPLC) are widely used to monitor the presence of these compounds in water, soils, foods, fruits and vegetables. Several recent papers have reported advances in this field ${ }^{[2,3-8]}$.

In the present study, a method employing HPLC with UV detection for the separation, identification and quantification of four widely used pesticides on cauliflower was developed and validated. The compounds studied were diazinon, malathion, chlorpyrifos and cypermethrin. Finally, the method was applied to the determination of these pesticides in commercial samples collected from the local markets. Therefore, the purpose of this study was to develop an analysis scheme for determination of some pesticides in cauliflower by HPLC. And this method provides accurate results for a variety of pesticides present in cauliflower.

\section{MATERIALS AND METHODS}

Sample material: Cauliflower was grown in the experimental field of Bangladesh Agricultural Research Institute (BARI). Four different areas were selected for application of 4 modern pesticides, diazinon, malathion, chlorpyrifos and cypermethrin before harvesting the samples. The matured Cauliflower bearing plants sprayed with the recommended dose $\left(1.7 \mathrm{~L} \mathrm{~h}^{-1}\right)$ and double of the recommended dose $\left(3.4 \mathrm{~L} \mathrm{~h}^{-1}\right)$ were collected from the field at the same day $6 \mathrm{~h}$ after spraying diazinon in the field. Samples of cauliflower sprayed with the recommended dose $\left(1.12 \mathrm{~L} \mathrm{~h}^{-1}\right)$ and double of the recommended dose $\left(2.24 \mathrm{~L} \mathrm{~h}^{-1}\right)$ were collected from the field at the same day $6 \mathrm{~h}$ after spraying malathion in the field. Likewise, samples of cauliflower sprayed with chlorpyrifos at the recommended dose $\left(0.25 \mathrm{~L} \mathrm{~h}^{-1}\right)$ and double of the recommended dose $\left(0.5 \mathrm{~L} \mathrm{~h}^{-1}\right)$ and another set of samples of cauliflower treated with cypermethrin at the recommended dose $\left(0.6 \mathrm{~L} \mathrm{~h}^{-1}\right)$ and double of the recommended dose $\left(1.2 \mathrm{~L} \mathrm{~h}^{-1}\right)$ were collected from the field at the same day $6 \mathrm{~h}$ after spraying pesticide in the field. Commercial samples of cauliflower were collected from different markets of Dhaka city (Nondon, Minabazar, Agora and PQS). The analysis conducted from January 2005 to May 2005.

Chemicals and reagents: The organic solvents, acetonitrile, ethyl acetate used were HPLC grade and were purchased from E. Merck. Technical grade pesticide standards were obtained from Bangladesh Agricultural Research Institute (BARI) with a purity of 95-99\%. The standards were stored in a freezer at $-5^{\circ} \mathrm{C}$. Ultra high quality water was obtained from Milli-Q water purification system (Millipore, Bedford, MA, USA). Mili-Q Water and acetonitrile were degassed by vacuum suction. All samples and solvents were filtered through Millipore membrane filters (Polysulfone membrane and $0.45 \mu \mathrm{m}$ pore size) before injection on the column. Anhydrous sodium sulphate for residue analysis, 12-60 mesh, was maintained at $300^{\circ} \mathrm{C}$ overnight. A source of pure nitrogen was used for evaporation to dryness in the extraction step.

Standard preparation: For preparation of stock solution, standards were dissolved in acetonitrile and four levels of intermediate standard solutions of each pesticide were prepared maintaining the same matrix concentration for the preparation of calibration curve and stored at $4^{\circ} \mathrm{C}$ in the dark. Working solutions were prepared daily by appropriate dilution with acetonitrile.

Extraction: Edible part of each vegetable sample (75 g) was cut into small pieces and homogenized by means of a kitchen blender and kept in a freezer by wrapping with clean airtight polythene bag (zip lock) at temperature below $-15^{\circ} \mathrm{C}$. The blended cauliflower 
sample $(75 \mathrm{~g})$ was mixed with anhydrous sodium sulphate $(50 \mathrm{~g})$ and extracted with ethyl acetate ${ }^{[9]}$ (200 $\mathrm{mL})$ in a conical flask using an Ultra-Turrax (IKA-WERK) for 4-5 min. The content was allowed to settle down for about half an hour and the ethyl acetate extract was then filtered through a Buchner-funnel fitted with a filter paper covered by $20 \mathrm{~g}$ of anhydrous sodium sulphate. After filtration, the extract was evaporated to dryness and re-dissolved in $5 \mathrm{~mL}$ of acetonitrile $(\mathrm{MeCN})$ and finally the volume was made up to $2 \mathrm{~mL}$ using rotary vacuum evaporator. The extract was then transferred to a graduated test tube and the final volume was adjusted at exactly $2 \mathrm{~mL}$ by adding a few drops of acetonitrile. Solutions were then centrifuged and filtered. The clean organic layers were taken and were analyzed by a high performance liquid chromatography having UV/Visible detector.

HPLC systems: A Shimadzu SCL-10AVP, Version 5.22 High performance liquid chromatography having UV/visible detector was used for identification and quantification of pesticides. Separation was performed on reversed phase C-18 column (Nova pack). Samples were injected manually through a Rheodyne injector. Detector was connected to the computer for data processing. The working condition of HPLC was binary gradient, mobile phase was acetonitrile: water; (70:30),

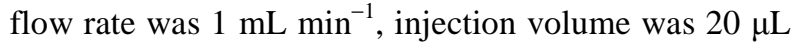
and the wavelength of the UV/visible detector was fixed at $254 \mathrm{~nm}$ for the residual analysis of Diazinon and $230 \mathrm{~nm}$ for the analysis of other three pesticides i.e., malathion, chlorpyrifos and cypermethrin.

Identification and quantification: The compound was identified by comparing its retention time with respect to technical grade reference standard. The quantitative determination was carried out with the help of a calibration curve drawn from chromatographic experiments with standard solution. For quantification an external calibration curve with four different concentrations of each pesticide, with matrix matching were made. The standard solutions for the calibration curves were prepared in control matrix because samples may possess co extractants in the matrix which may affect the peak area of the unknown samples.

Recovery: Recovery studies were performed to examine the efficacy of extraction and clean up. Untreated cauliflowers were spiked with known concentration of the pure insecticide standard solution of each type of pesticide and extraction and clean-up were performed as described earlier. The concentration of each pesticide in the final extracts was calculated.
Statistical analysis: External calibration and recovery teses were performed. The residue results were the means from three replicates of each treatment and all data's were analyzed using simple descriptive statistics such as means, standard deviations, using Kaleidagraph version 4 for windows.

\section{RESULTS}

Limit Of Detection (LOD) was calculated from the peak intensity at $0.1 \mathrm{mg} \mathrm{kg}^{-1}$ and blank levels in recovery tests. LOD was defined as $\mathrm{S} / \mathrm{N}>4$ so that it is in the linear range of the standard calibration. The LOD of diazinon, Malathion, chlorpyrifos and cypermethrin was $0.02 \mathrm{mg} \mathrm{kg}^{-1}$. Recoveries which were obtained by triplicate analysis of cauliflower sample spiked with each type of pesticide at one fortification level were satisfactory for residue analysis and are of the same order as those obtained by using more complicated methodologies. The percent recoveries for diazinon, malathion, chlorpyrifos and cypermethrin were 106.0, 91.0, 81.7 and 93.6, respectively. Residues were corrected according to the average of recovery. Linear calibration curves were found between peak areas and analyte concentration in the whole range studied. The linear regression $(y=a+b x)$ parameters for method calibration are shown in Table 1 . The determination coefficients $\left(\mathrm{R}^{2}\right)$ of analytical curves were near 0.99 , with linearity for each compound, which allows the quantitation of these compounds by the method of external standardization.

Diazinon and chlorpyrifos were detected in all samples (Table 2). It is found that diazinon was detected above Maximum Residue Limit (0.01 $\mathrm{mg} \mathrm{kg}^{-1}$ of sample $)^{[10]}$ in the samples where diazinon was sprayed at the recommended dose and double of the

Table 1:Retention Times Windows (RTWs) and typical calibration parameters of the method in cauliflower matrix

\begin{tabular}{|c|c|c|c|c|c|}
\hline \multirow[b]{2}{*}{ Compound } & \multirow[b]{2}{*}{ RT (Min) } & \multirow{2}{*}{$\begin{array}{l}\text { Calibration } \\
\text { range } \\
\left(\mathrm{mg} \mathrm{kg}^{-1}\right)\end{array}$} & \multicolumn{3}{|c|}{ Calibration parameters } \\
\hline & & & Slope & Intercept & $\mathrm{R}^{2}$ \\
\hline Diazinon & 8.1 & $0.066-1.46$ & $1.3 \times 10^{5}$ & 65000 & 0.998 \\
\hline Malathion & 5.7 & $0.080-1.66$ & $4.5 \times 10^{4}$ & 43000 & 0.992 \\
\hline Chlorpyrifos & 12.9 & $0.076-1.15$ & $3.9 \times 10^{4}$ & 54000 & 0.991 \\
\hline Cypermethrin & 9.8 & $0.064-0.99$ & $8.27 \times 10^{4}$ & 18400 & 0.988 \\
\hline
\end{tabular}

Table 2: Amounts of residues detected in cauliflower samples treated with the respective pesticide

Residue $\left(\mathrm{mg} \mathrm{kg}^{-1}\right)$

\begin{tabular}{lllll} 
Dose & Diazinon & Malathion & Chlorpyrifos & Cypermethrin \\
\hline $\begin{array}{l}\text { Recommended dose } \\
\begin{array}{l}\text { Double of the } \\
\text { Recommended dose }\end{array}\end{array}$ & 1.085 & ND & 1.628 & ND \\
\hline
\end{tabular}

$\mathrm{ND}=$ Not detected i.e., below detection level of $0.02 \mathrm{mg} \mathrm{kg}^{-1}$ 
Am. J. Environ. Sci., 5 (3): 325-329, 2009

Table 3: Amounts of residues in the four different samples of cauliflower collected from different markets area of sample Residue $\left(\mathrm{mg} \mathrm{kg}^{-1}\right)$

\begin{tabular}{lllll} 
Collection & Diazinon & Malathion & Chlorpyrifos & Cypermethrin \\
\hline Nondon & ND & ND & ND & ND \\
Minabazar & ND & ND & ND & ND \\
Agora & ND & ND & ND & ND \\
PQS & ND & ND & ND & ND
\end{tabular}

$\mathrm{ND}=$ Not detected i.e., below detection level of $0.02 \mathrm{mg} \mathrm{kg}^{-1}$

recommended dose. The amount of the residues of diazinon at the recommended dose was $1.085 \mathrm{mg} \mathrm{kg}^{-1}$ and the double of the recommended dose was $1.64 \mathrm{mg} \mathrm{kg}$. Similarly chlorpyrifos was detected above the Maximum Residue Limit $\left(0.05 \mathrm{mg} \mathrm{kg}^{-1}\right.$ of sample $)^{[11]}$ in the samples where chlorpyrifos was sprayed at the recommended dose and double of the recommended dose. The amount of the residues of chlorpyrifos present at the recommended dose is $1.62 \mathrm{mg} \mathrm{kg}^{-1}$ and the double of the recommended dose is $2.243 \mathrm{mg} \mathrm{kg}^{-1}$. According to the results, malathion and cypermethrin were not detected in the samples because they were present in the samples below our detection level $\left(0.02 \mathrm{mg} \mathrm{kg}^{-1}\right)$. It is found that no pesticide residues were present in the commercial samples collected from different markets of Dhaka city (Table 3).

\section{DISCUSSION}

Diazinon may decompose in plants in two directions. One of them may be oxidation of the phosphorothioate to the corresponding phosphate (diazinon) followed by hydrolysis of the P-X bond with the formation of non toxic diethylphosphoric acid and 2-isopropyl -4-methyl-6-0xypyrimidine and the another direction of the decomposition of diazinon may be the oxidation of the side isopropyl group of the ring with the subsequent hydrolysis of the phosphorus halogen bond with decomposition of the heterocyclic ring and the liberation of carbon dioxide gas. Diazinon is highly toxic to humans and animal. So the recommended dose which is applied by the farmer in the field to control the pests in cauliflower should be lower. Chlorpyrifos may decomposes in plants and may produce chlorpyrifosoxon and 3, 5, 6-trichloro-2-pyridinol, which is further degraded to 3, 5, 6-trichloro-2-methoxypyridine and carbon dioxide ${ }^{[12]}$. Chlorpyrifos are highly toxic to human and animal. So, the recommended dose of the chlorpyrifos in cauliflower should be lower.

Traces of malathion are commonly found on regions of the plants having a high fat or lipid content.
Degradation on plants increased with moisture content. In plant's tissues, malathion may intensively hydrolyzed by phosphatases and carboxyesterases along the P-X bond and ester to form dimethyl phosphorothiotioic and others acids having a low toxicity. The rapid losses which occur on the plant before harvesting appear to be due to a number of factors including evaporation, chemical decomposition of surface deposits and metabolism within plant ${ }^{[13]}$. Cypermethrin may photo degrades rapidly. After photo degradation cypermethrin may produce DCVA, 3phenoxybenzaldehyde and 3-phenoxybenzoic acids ${ }^{[14]}$. Cypermethrin may also subject to microbial degradation. To avoid any contamination malathion and cypermethrin sprayed cauliflower should be harvested after few days. Factors mentioned above, may contribute to increasing degradation of malathion and cypermethrin resulting on residues below detection limit.

Since the organophosphorus and pyrethroid pesticides residues are not degraded into non toxic products in short period of time. They still persisted in vegetable. So the recommended dose, which is applied by the farmer in the field to control pests in cauliflower, should be lower or pre-harvest interval should be longer.

\section{CONCLUSION}

In Bangladesh context, the Cauliflower growers have been using the pesticides frequently to have the higher and insect free yield. But the overdoses of pesticides make the residue problem, which might pollute our food and environment. Appropriate use of pesticides in agriculture needs to be addressed in Bangladesh and other countries. Although the Government is concerned about pesticide residues in the food and the environment, staff and facilities to conduct the necessary monitoring programs are not available. In addition the country is not yet established legal limits for residues and depends upon Codex allowable limit which are not always proposed for all crops and major pesticides used with in the country. So in order to remove residual effect of pesticides which are toxic, we should know the exact dose which should be recommended to the farmer and the harvest time of each pesticides so that the amount of residual pesticides in vegetables might be lower than the present time. And an attractive method was provided by this approach with detection limits at parts per million concentrations and could be extended to additional crops and pesticides. 
Am. J. Environ. Sci., 5 (3): 325-329, 2009

\section{ACKNOWLEDGEMENT}

Researchers gratefully acknowledge Dr. Katsumi Ishikawa for his advice and critical reading of the Manuscript.

\section{REFERENCES}

1. Cauliflower, 2005. Banglapedia: National Encyclopedia of Bangladesh. http://banglapedia.search.com.bd/HT/C_0062.htm

2. Melo, L.F.C., C.H. Collins and I.C.S.F. Jardim, 2004. New materials for solid-phase extraction and multiclass high-performance liquid chromatographic analysis of pesticides in grapes. J. Chromatogr. A., 1032: 51-58. DOI: 10.1016/J.CHROMA.2003.10.101

3. Blasco, C., G. Font and Y. Pico, 2004. Determination of dithiocarbamates and metabolites in plants by liquid chromatography-mass spectrometry. J. Chromatogr. A., 1028: 267-276. DOI: 10.1016/J.CHROMA.2003.12.002

4. Singh, S.B., G.D. Foster and S.U. Khan, 2004. microwave-assisted extraction for the simultaneous determination of thiamethoxam, imidacloprid and carbendazim residues in fresh and cooked vegetable samples. J. Agric. Food Chem., 52: 105-109. DOI: $10.1021 / \mathrm{jf030358p}$

5. Gennaro, M.C., E. Marengo, V. Gianotti, S. Angioi and G. Copeta, 2003. Intercalibration of chromatographic methods for auxino phytodrugs in Solanaceae. J. Chromatogr. A., 993: 111-119. DOI: $10.1016 / \mathrm{S} 0021-9673(03) 00332-7$

6. Habib, J., I. Hofer and J.M. Renaud, 2003. Analysis of multiple pesticide residues in tobacco using pressurized liquid extraction, automated solid-phase extraction clean-up and gas chromatography-tandem mass spectrometry. J. Chromatogr. A., 1020: 173-187. DOI: 10.1016/J.CHROMA.2003.08.049

7. Caballo-lopez, A. and M.D.L. De Castro, 2003. Continuous ultrasound-assisted extraction coupled to on line filtration-solid-phase extraction-column liquid chromatography-post column derivatisationfluorescence detection for the determination of $\mathrm{N}$ methyl carbamates in soil and food. J. Chromatogr. A., 998: 51-59. DOI: 10.1016/S00219673(03)00646-0
8. Oetero, R.R. and B.C. Grande, 2003. Multiresidue method for fourteen fungicides in white grapes by liquid-liquid and solid-phase extraction followed by liquid chromatography-diode array detection. J. Chromatogr. A., 992: 121-131. DOI: 10.1016/S0021-9673(03)00317-0

9. Islam, S., M.S. Hossain, N. Nahar, M. Mosihuzzaman and M.I.R. Mamun, 2009. Application of high performance liquid chromatography to the analysis of pesticide residues in Eggplants. J. Applied Sci., 9: 973-977. DOI: 10.3923/jas.2009.973.977

10. MRL Status Report, 2009. Agri business systems international.

http://www.nda.agric.za/docs/Plantquality/Info\%20 HUB/Brassica\%20Veg\%20files/Cauliflower\%20M RL\%20Datasheet.pdf

11. FAO/WHO Standards, 2008. Pesticide residues in food. Maximum residue limits. CODEX Alimentarius.

http://www.codexalimentarius.net/mrls/pestdes/jsp/ pest_q-e.jsp

12. Racke, K.D., 1993. Environmental fate of chlorpyrifos. Rev. Environ. Contam. Toxicol., 131: 1-154.

http://www.ncbi.nlm.nih.gov/pubmed/7678349?do $\mathrm{pt}=\mathrm{Abstract}$

13. Kovistoinen, P., A. Karinppa and M. Kononen, 1964. Insecticide Residues, Disappearance Rates of Malathion Residues as Affected by Previous Treatments with Paraoxon, Parathion and Malathion. J. Agric. Food Chem., 12: 555-557. DOI: $10.1021 / \mathrm{jf} 60136 \mathrm{a} 020$

14. Otieno, D.A. and Gerald Pattenden, 1980. Degradation of the natural pyrethroids. Pesticide Sci., 11: 270-278. DOI: 10.1002/ps.2780110220 